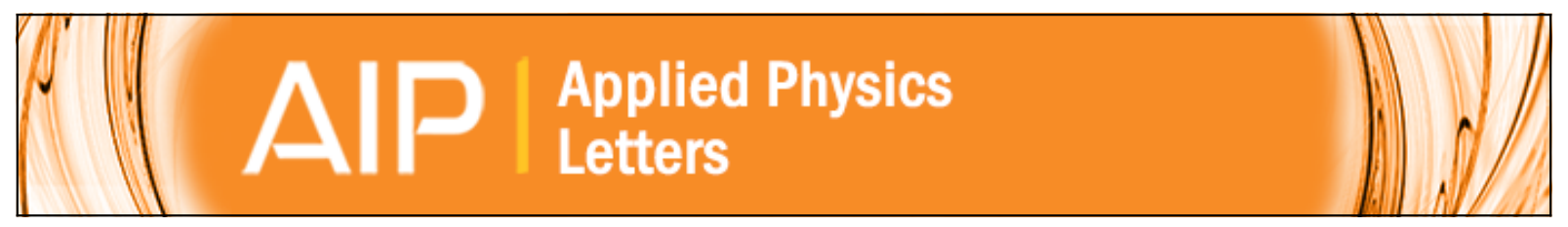

\title{
Exchange-diffusion reactions in HfSiON during annealing studied by Rutherford backscattering spectrometry, nuclear reaction analysis and narrow resonant nuclear reaction profiling
}

L. Miotti, K. P. Bastos, G. V. Soares, C. Driemeier, R. P. Pezzi, J. Morais, I. J. R. Baumvol, A. L. P. Rotondaro, M. R. Visokay, J. J. Chambers, M. Quevedo-Lopez, and L. Colombo

Citation: Applied Physics Letters 85, 4460 (2004); doi: 10.1063/1.1812814

View online: http://dx.doi.org/10.1063/1.1812814

View Table of Contents: http://scitation.aip.org/content/aip/journal/apl/85/19?ver=pdfcov

Published by the AIP Publishing

\section{Articles you may be interested in}

Mg segregation in Mg-rich Mg-Ni switchable mirror studied by Rutherford backscattering, elastic recoil detection analysis, and nuclear reaction analysis

J. Appl. Phys. 106, 114912 (2009); 10.1063/1.3267481

Depth profiling of chemical states and charge density in HfSiON by photoemission spectroscopy using synchrotron radiation

Appl. Phys. Lett. 92, 082903 (2008); 10.1063/1.2841705

Oxygen reaction-diffusion in metalorganic chemical vapor deposition $\mathrm{HfO} 2$ films annealed in $\mathrm{O} 2$

Appl. Phys. Lett. 81, 1669 (2002); 10.1063/1.1502006

Damage evolution and recovery on both $\mathrm{Si}$ and $\mathrm{C}$ sublattices in Al-implanted $4 \mathrm{H}-\mathrm{SiC}$ studied by Rutherford backscattering spectroscopy and nuclear reaction analysis

J. Appl. Phys. 91, 6388 (2002); 10.1063/1.1469204

Investigation of alkali ion exchange processes in waste glasses using Rutherford backscattering spectrometry and nuclear reaction analysis

AIP Conf. Proc. 576, 454 (2001); 10.1063/1.1395347

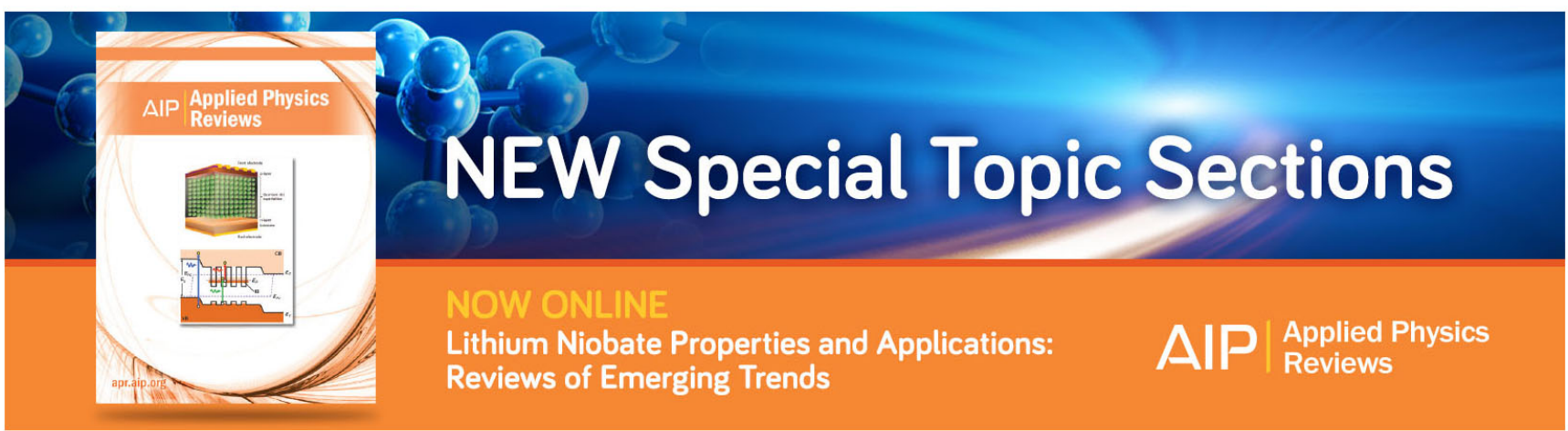




\title{
Exchange-diffusion reactions in HfSiON during annealing studied by Rutherford backscattering spectrometry, nuclear reaction analysis and narrow resonant nuclear reaction profiling
}

\author{
L. Miotti, K. P. Bastos, G. V. Soares, C. Driemeier, R. P. Pezzi, and J. Morais \\ Instituto de Física-UFRGS, CP 15051 Porto Alegre 91501-970, Brazil \\ I. J. R. Baumvol \\ Centro de Ciencias Exatas e Tecnologicas-UCS, 95070-560 Caxias do Sul, Brazil
}

\begin{abstract}
A. L. P. Rotondaro, ${ }^{a)}$ M. R. Visokay, J. J. Chambers, M. Quevedo-Lopez, and L. Colombo Silicon Technology Development, Texas Instruments Incorporated, Dallas, Texas
\end{abstract}

(Received 21 June 2004; accepted 1 September 2004)

\begin{abstract}
HfSiON films deposited on $\mathrm{Si}(001)$ by reactive sputtering were submitted to rapid thermal annealing at $1000{ }^{\circ} \mathrm{C}$ in vacuum, $\mathrm{N}_{2}$ and $\mathrm{O}_{2}$ atmospheres. The stability of the dielectric was evaluated by measuring the atomic transport and exchange of the chemical species, using Rutherford backscattering spectrometry, nuclear reaction analysis and narrow resonant nuclear reaction profiling. Annealing in $\mathrm{O}_{2}$ ambient reduced the $\mathrm{N}$ concentration mainly from near-surface regions where oxygen was incorporated in comparable amounts. Vacuum annealing, on the other hand, induced $\mathrm{N}$ loss preferentially from the $\mathrm{Si} /$ dielectric interface and $\mathrm{O}$ loss preferentially from near-surface regions. The results are explained in terms of exchange-diffusion reactions occurring in the HfSiON. (c) 2004 American Institute of Physics. [DOI: 10.1063/1.1812814]
\end{abstract}

The use of metal oxide and silicate films on Si as a high$k$ gate dielectric replacement for silicon dioxide and oxynitride in advanced ultralarge scale integration technologies presents several difficulties. Some of the key topics of concern are: density of interface states, reliability, chemical and structural stability, oxidation of the Si substrate, diffusion of metallic species into the active semiconductor region and transport of $\mathrm{Si}$ into the high- $k$ film. ${ }^{1-3}$ Recent investigations $^{4-9}$ indicate that incorporation of nitrogen into the hafnium oxide and silicate films either during or after deposition, by plasma or thermal treatments, leads to superior thermal stability, overcoming many of the abovementioned difficulties. However, since $\mathrm{N}$ is mainly incorporated into metastable configurations in the oxide and silicate films ${ }^{9-11}$ (pseudo-ternary character, $\left.\left[\mathrm{HfO}_{2}\right]_{x}\left[\left(\mathrm{SiO}_{2}\right)_{1-y}\left(\mathrm{Si}_{3} \mathrm{~N}_{4}\right)_{y}\right]_{1-x}\right)$, the integration of $\mathrm{N}$ containing high- $k$ dielectrics into the metal oxide semiconductor field effect transistor fabrication flow relies on the stability of $\mathrm{N}$ during further high temperature processing steps. Indeed, structural degradation, more specifically recrystallization of the amorphous high- $k$ films, ${ }^{4}$ has been observed in those regions of the high- $k$ film from where the $\mathrm{N}$ is low either intentionally or as a result of annealing in an oxidizing environment. Nitrogen loss also gives rise to lower capacitance which is usually a result of a lower dielectric constant. In this letter, we report on $\mathrm{N}, \mathrm{O}, \mathrm{Si}$, and $\mathrm{Hf}$ atomic transport and exchange during thermal annealing of heavily nitrided hafnium silicate (HfSiON) films on $\mathrm{Si}$. The $\mathrm{Si}(100)$ substrate was cleaned by standard $\mathrm{NH}_{4} \mathrm{OH}: \mathrm{H}_{2} \mathrm{O}_{2}: \mathrm{H}_{2} \mathrm{O}$ cleaning followed by etching in a 100:1 diluted HF solution, resulting in a hydrogen terminated surface. ${ }^{12}$ The films were deposited by reactive sputtering from an HfSi target. These films were submitted to different rapid thermal annealing (RTA) se-

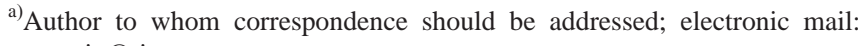
antonio@ti.com quences at $1000{ }^{\circ} \mathrm{C}$ in vacuum, $\mathrm{N}_{2}$ flow, and 7 mbar of $97 \%$ ${ }^{18} \mathrm{O}$-enriched $\mathrm{O}_{2}$ atmospheres (vacuum-, $\mathrm{N}_{2^{-}}$, and ${ }^{18} \mathrm{O}_{2}$-annealing), respectively, for different times. The aim of the present study is an atomic scale observation and understanding of the $\mathrm{N}$ losses reported previously, ${ }^{4,8}$ as well as the oxygen and nitrogen diffusion and eventual incorporation into the Si substrate during the different thermal processing routes.

The areal densities of $\mathrm{Hf}$ and $\mathrm{Si}$ and the profiles of $\mathrm{Hf}$ were determined by Rutherford backscattering spectrometry (RBS) in channeled or high-tilt geometries. The areal densities of ${ }^{16} \mathrm{O},{ }^{18} \mathrm{O}$, and $\mathrm{N}$ were determined by nuclear reaction analysis (NRA) from the plateau regions of the cross section curves using the ${ }^{16} \mathrm{O}(d, p){ }^{17} \mathrm{O},{ }^{18} \mathrm{O}(p, \alpha){ }^{15} \mathrm{~N}$, and ${ }^{14} \mathrm{~N}(d, \alpha){ }^{12} \mathrm{C}$ reactions, respectively. ${ }^{13}$ Nitrogen, ${ }^{18} \mathrm{O}$ and $\mathrm{Si}$ were profiled with subnanometric depth resolution by nuclear narrow resonant reaction profiling (NRP) using the ${ }^{15} \mathrm{~N}(p, \gamma){ }^{12} \mathrm{C},{ }^{18} \mathrm{O}(p, \alpha){ }^{15} \mathrm{~N}$, and ${ }^{29} \mathrm{Si}(p, \gamma){ }^{30} \mathrm{P}$ reactions, near the respective resonances of 429,151 , and $414 \mathrm{keV} .{ }^{13}$

Figure 1 shows the RBS spectra for the as-deposited and $\mathrm{N}_{2}$-annealed samples for $60 \mathrm{~s}$, in the highly tilted $\left[70^{\circ}\right.$ tilt, $165^{\circ}$ detection with respect to the incident beam, Fig. 1(a)] and in the channeling-grazing angle detection [Fig. 1(b)] geometries. The Hf signal shows the usual 3\% $\mathrm{Zr}$ contribution. The Hf and Si signals in the tilted RBS spectra do not change after $\mathrm{N}_{2}$ annealing, as well as after any of the other annealing sequences performed (not shown). Based on these observations we concluded that $\mathrm{Hf}$ and $\mathrm{Si}$ are immobile within the accuracy (3\% and 5\%, respectively) and depth resolution ( $2 \mathrm{~nm}$ ) of the technique. From the channeled-RBS spectrum [Fig. 1(b)] and the NRA results described below, the composition of the dielectric is extracted and found to be approximately equal to $\mathrm{HfSi}_{1.5} \mathrm{~N}_{2.3} \mathrm{O}_{0.1}$ for the as-deposited films.

The areal densities of $\mathrm{N}$ and ${ }^{18} \mathrm{O}$ as determined by NRA in the as-deposited and $\mathrm{N}_{2}$-annealed samples, both submitted to a further ${ }^{18} \mathrm{O}_{2}$ annealing for increasing time intervals, are 

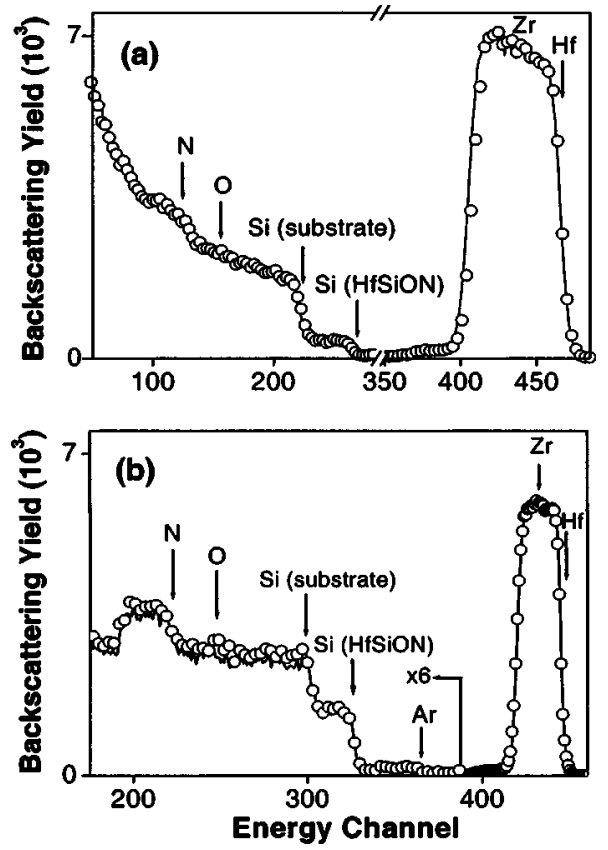

FIG. 1. Backscattering spectra of $1 \mathrm{MeV}$ incident $\mathrm{He}^{+}$ions from asdeposited (solid line) and rapid thermal annealed in $\mathrm{N}_{2}$ at $1000{ }^{\circ} \mathrm{C}$ for $60 \mathrm{~s}$ (empty circles), from HfSiON films on $\mathrm{Si}(001)$ in two different geometries as shown in the insets: (a) $70^{\circ}$ tilt and detection at $165^{\circ}$ with respect to the direction of incidence and (b) channeling in the $\langle 001\rangle$ axis of the Si substrate and detection at $110^{\circ}$ with respect to the direction of incidence. The arrows indicate the energy position of the elements at the sample surface or interface.

given in Fig. 2. One can see substantial $\mathrm{N}$ loss, which qualitatively corresponds to the same amounts of ${ }^{18} \mathrm{O}$ incorporated in the films. It is also found that vacuum and $\mathrm{N}_{2}$ annealing induce much smaller $\mathrm{N}$ and $\mathrm{O}$ losses than annealing in oxygen (see Fig. 4).

Figure 3 shows the ${ }^{18} \mathrm{O}$ and ${ }^{15} \mathrm{~N}$ NRP excitation curves and the corresponding profiles in the insets, for the asdeposited and $\mathrm{N}_{2}$-annealed samples, before and after ${ }^{18} \mathrm{O}_{2}$ annealing for the same time intervals as in Fig. 2. The $\mathrm{N}$ profile for the as-deposited sample drops abruptly at the interface with the $\mathrm{Si}$ substrate, while for the $\mathrm{N}_{2}$-annealed sample, a slight homogeneous $\mathrm{N}$ loss, with a small tail penetrating into the Si substrate, is observed. The effects of ${ }^{18} \mathrm{O}_{2}$

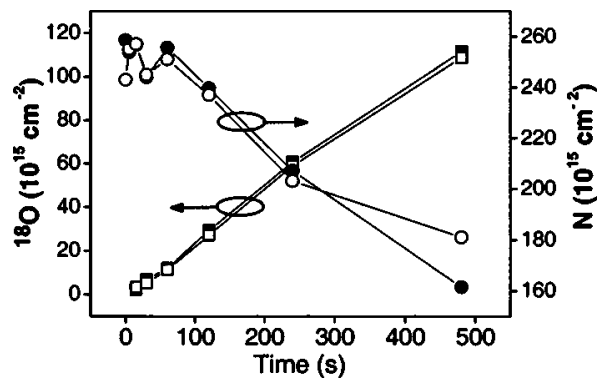

FIG. 2. Areal densities of ${ }^{18} \mathrm{O}$ and $\mathrm{N}$ as determined by nuclear reaction analysis in as-deposited $\left({ }^{18} \mathrm{O}\right.$ empty squares, $\mathrm{N}$ empty circles) and $\mathrm{N}_{2}$-annealed ( ${ }^{18} \mathrm{O}$ solid square $\mathrm{N}$ solid circles) $\mathrm{HfSiON}$ films on $\mathrm{Si}(001)$ submitted to rapid thermal annealing at $1000{ }^{\circ} \mathrm{C}$ in $97 \%{ }^{18} \mathrm{O}$-enriched $\mathrm{O}_{2}$ for different times.

annealing are: (i) a propagation of ${ }^{18} \mathrm{O}$ front from the film surface, leading to ${ }^{18} \mathrm{O}$ incorporation in the films, from the near-surface regions up to the $\mathrm{HfSiON} / \mathrm{Si}$ interface for the two longest annealing times, and oxidation of the Si substrate, (ii) removal of $\mathrm{N}$ from those regions where ${ }^{18} \mathrm{O}$ is incorporated, in comparable amounts as the ${ }^{18} \mathrm{O}$ incorporation, (iii) removal of comparatively smaller $\mathrm{N}$ amounts from those regions where ${ }^{18} \mathrm{O}$ was not incorporated, and (iv) diffusion of $\mathrm{N}$ into the $\mathrm{Si}$ substrate to progressively larger depths, most probably forming ${ }^{4,9-11} \mathrm{Si}-\mathrm{N}$ bonds.

The effects of vacuum annealing are illustrated in Fig. 4 for as-deposited and $\mathrm{N}_{2}$-annealed samples subjected to two different further annealing sequences, namely ${ }^{18} \mathrm{O}_{2}$ annealing and ${ }^{18} \mathrm{O}_{2}$ annealing + vacuum annealing. Vacuum annealing induces ${ }^{18} \mathrm{O}$ loss preferentially from near-surface regions and no ${ }^{18} \mathrm{O}$ loss from near-interface regions. Nitrogen loss due to vacuum annealing is moderate and, contrary to ${ }^{18} \mathrm{O}$ loss; it takes place preferentially at the $\mathrm{HfSiON} / \mathrm{Si}$ interface region. In fact, the concentration of $\mathrm{N}$ in near-surface regions increases slightly after vacuum annealing.

Most of the diffusing nitrogenous species are lost by desorption from the film surface with a minor portion penetrating into the Si substrate. This effect is substantially enhanced by the chemical reaction ${ }^{14}$ during ${ }^{18} \mathrm{O}_{2}$ annealing. The $\mathrm{Si}-\mathrm{N}$ and $\mathrm{Hf}-\mathrm{Si}-\mathrm{N}$ bonds are dissociated through a chemical (exchange) reactions like $\mathrm{Si}-\mathrm{N}+{ }^{18} \mathrm{O}_{2} \rightarrow \mathrm{Si}-{ }^{18} \mathrm{O}$ $+\mathrm{N}^{18} \mathrm{O}$, where $\mathrm{N}$ is exchanged for ${ }^{18} \mathrm{O}$ in the HfSiON net-
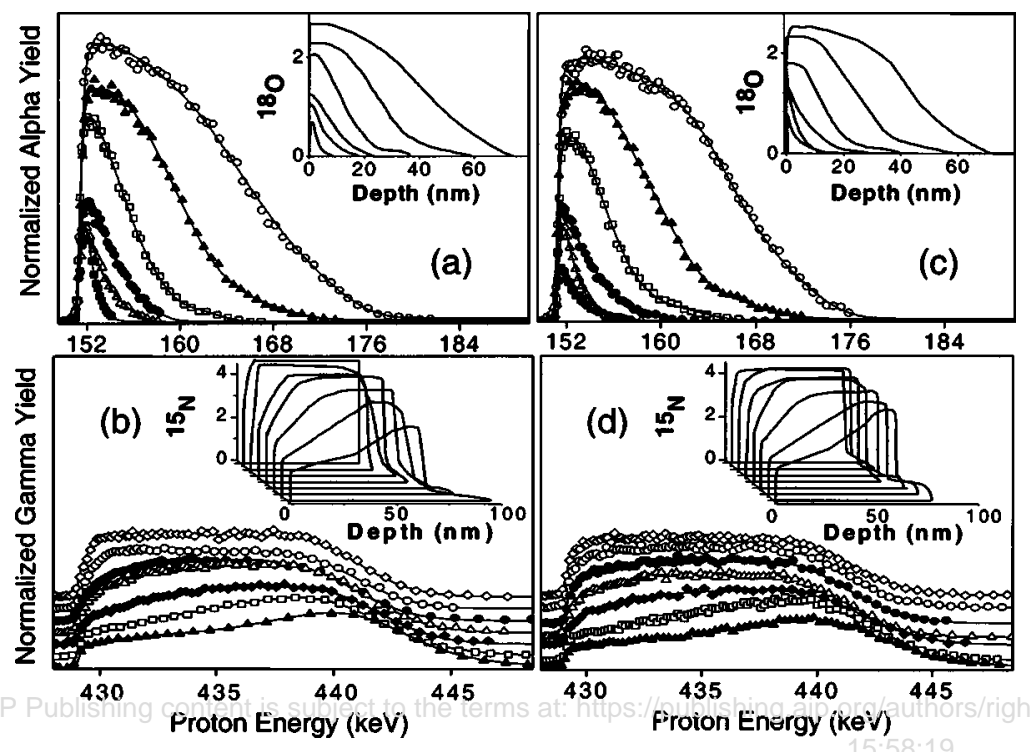

FIG. 3. Excitation curves of the ${ }^{18} \mathrm{O}(p, \alpha){ }^{15} \mathrm{~N}$ and ${ }^{15} \mathrm{~N}(p, \alpha \gamma)^{12} \mathrm{C}$ nuclear reactions near the resonances at 151 and $429 \mathrm{keV}$, respectively, from as-deposited [left, (a) and (b)] and $\mathrm{N}_{2}$-annealed [right, (c) and (d)] Hf$\mathrm{SiON}$ films on $\mathrm{Si}(001)$ submitted to rapid thermal annealing at $1000{ }^{\circ} \mathrm{C}$ in $97 \%{ }^{18} \mathrm{O}$-enriched $\mathrm{O}_{2}$ for 15,30 , $60,120,240$, and $480 \mathrm{~s}$. The vertical scales of the ${ }^{15} \mathrm{~N}$ excitation curves are shifted. The corresponding profiles are shown in the insets, with ${ }^{18} \mathrm{O}$ and ${ }^{15} \mathrm{~N}$ concentrations in units of $10^{22} \mathrm{~cm}^{-3}$. Before ${ }^{18} \mathrm{O}_{2}$ annealing, only the $\mathrm{N}$ excitation curves and profiles were determined. The rapid thermal annealing times increase from top to bottom in the figures and from back to front in the insets. 


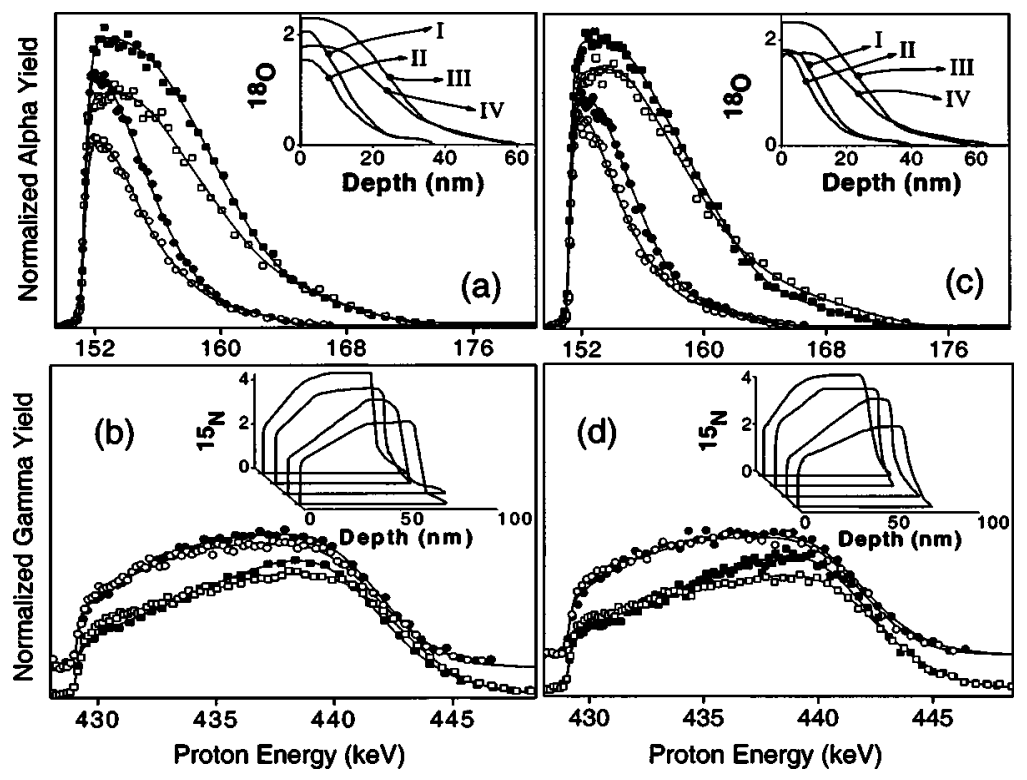

FIG. 4. Excitation curves of the ${ }^{18} \mathrm{O}(p, \alpha){ }^{15} \mathrm{~N}$ and ${ }^{15} \mathrm{~N}(p, \alpha \gamma){ }^{12} \mathrm{C}$ nuclear reactions near the resonances at 151 and $429 \mathrm{keV}$, respectively, from as-deposited [left, (a) and (b)] and $\mathrm{N}_{2}$-annealed [right, (c) and (d)] HfSiON films on Si (001) submitted to rapid thermal annealing at $1000{ }^{\circ} \mathrm{C}$ in $97 \%{ }^{18} \mathrm{O}$-enriched $\mathrm{O}_{2}$ for $120 \mathrm{~s}$ (curve I) and $240 \mathrm{~s}$ (curve III) and further annealed in vacuum at $1000{ }^{\circ} \mathrm{C}$, for 120 and $240 \mathrm{~s}$, respectively (curves II and IV). The vertical scales of the ${ }^{15} \mathrm{~N}$ excitation curves are shifted. The corresponding profiles are shown in the insets, with ${ }^{18} \mathrm{O}$ and $\mathrm{N}$ concentrations in units of $10^{22} \mathrm{~cm}^{-3}$.

work, forming $\mathrm{N}^{18} \mathrm{O}$ that diffuses through the dielectric. ${ }^{15}$ This reaction-diffusion process results in a much larger $\mathrm{N}$ loss from the system, as well as in a larger $\mathrm{N}$ diffusion into the Si substrate. The similarity between the areal densities and profiles of incorporated ${ }^{18} \mathrm{O}$ and lost $\mathrm{N}$ confirm the substitution (exchange) reactions proposed above as the principal mechanism responsible for nitrogen loss and oxygen incorporation. Since N is also lost from near-interface regions of the films where, for the shortest ${ }^{18} \mathrm{O}_{2}$-annealing times, there was no ${ }^{18} \mathrm{O}$ incorporation, one can hypothesize that a thermally only induced dissociation and diffusion is acting in parallel to the reaction-diffusion process. Another aspect deserving consideration is the incorporation of $\mathrm{N}$ into the $\mathrm{Si}$ substrate after $\mathrm{N}_{2}$ annealing. In this case, substoichiometric $\mathrm{SiN}_{x}$ is formed at the $\mathrm{HfSiON} / \mathrm{Si}$ interface. On the other hand, in the case of ${ }^{18} \mathrm{O}_{2}$ annealing, the diffusion of NO-like molecules toward the $\mathrm{HfSiON} / \mathrm{Si}$ interface can lead, as it is well known, ${ }^{16}$ to the formation of silicon oxynitride compounds.

The observed $\mathrm{N}$ loss from near-interface regions after vacuum annealing of $\mathrm{HfSiON}$ films that were previously annealed in ${ }^{18} \mathrm{O}_{2}$ for long (120 s and more) RTA times is probably a consequence of the formation of a silicon oxynitride layer $(\mathrm{SiON})$ at the interface, constituting a diffusion barrier. ${ }^{1,17}$ The interface nitridation may limit further $\mathrm{N}$ transport across the interface and leads to loss from the surface only. On the other hand, ${ }^{18} \mathrm{O}$ loss from near-surface regions of these samples (as well as a slight increase of the $\mathrm{N}$ concentration), can be attributed to the inverse exchange reaction, namely fixed ${ }^{18} \mathrm{O}$ is now exchanged with $\mathrm{N}$ from near-interface regions, promoting a moderate increase in the $\mathrm{N}$ concentration in these regions and a comparable ${ }^{18} \mathrm{O}$ loss.

In summary, the simulation of a high temperature postdeposition processing step of $\mathrm{HfSiON}$ films on $\mathrm{Si}$ in different atmospheres revealed reaction-diffusion phenomena, leading to atomic transport and exchange of the chemical species present in the system. In the case of annealing in an oxygen atmosphere, $\mathrm{N}$ is lost in exchange for $\mathrm{O}$. Annealing in vacuum or nitrogen atmospheres promoted $\mathrm{N}$ and $\mathrm{O}$ losses from the system, although in much smaller amounts compared to the case of annealing in oxygen. A minor portion of the mobile nitrogenous species is transported across the
$\mathrm{HfSiON} / \mathrm{Si}$ interface, forming silicon nitrides or, alternatively, oxynitrides for the longest rapid thermal annealing times. The presence of silicon nitride and oxynitrides acts as a diffusion barrier in the near-interface region. The formation of the interfacial $\mathrm{SiON}$ modifies the reaction-diffusion dynamics, which results in a reduction in the transport of oxygen at the dielectric/substrate interface as compared to nonnitrided $\mathrm{HfSiO} / \mathrm{Si}$ interface.

${ }^{1}$ G. D. Wilk, R. M. Wallace, and J. M. Anthony, J. Appl. Phys. 89, 5243 (2001).

${ }^{2}$ A. I. Kingon, J.-P. Maria, and S. K. Streiffer, Nature (London) 406, 1032 (2000).

${ }^{3}$ M. Quevedo-Lopez, M. El-Bouanani, S. Addepalli, J. L. Duggan, B. E. Gnade, R. M. Wallace, M. R. Visokay, M. Douglas, and L. Colombo, Appl. Phys. Lett. 79, 4192 (2001).

${ }^{4}$ M. R. Visokay, J. J. Chambers, A. L. P. Rotondaro, A. Shanware, and L. Colombo, Appl. Phys. Lett. 80, 3183 (2002).

${ }^{5}$ A. L. P. Rotondaro, M. R. Visokay, J. J. Chambers, A. Shanware, R. Khamankar, H. Bu, R. T. Laaksonen, L. Tsung, M. Douglas, R. Kuan, M. J. Bevan, T. Grider, J. McPherson, and L. Colombo, in Symposium on VLSI Technology Digest of Technical Papers, Honolulu, HI, June 11-13, 2002, p. 148.

${ }^{6}$ A. Shanware, M. R. Visokay, J. J. Chambers, A. L. P. Rotondaro, H. Bu, M. J. Bevan, R. Khamankar, S. Aur, P. E. Nicollian, J. McPherson, and L. Colombo, in IEEE International Reliability Physics Symposium Proceedings, Dallas, TX, March 30-April 14, 2003, p. 208.

${ }^{7}$ M. S. Akbar, S. Gopalan, H.-J. Cho, K. Onishi, R. Choi, R. Nieh, C. S. Kang, Y. H. Kim, J. Han, S. Krishnan, and J. C. Lee, Appl. Phys. Lett. 82, 1757 (2003).

${ }^{8}$ M. Quevedo-Lopez, M. El-Bouanani, M. J. Kim, B. E. Gnade, R. M. Wallace, M. R. Visokay, A. LiFatou, J. J. Chambers, and L. Colombo, Appl. Phys. Lett. 82, 4669 (2003).

${ }^{9}$ C. Hinkle and G. Lucovsky, Appl. Surf. Sci. 216, 124 (2003).

${ }^{10}$ K. P. Bastos, J. Morais, L. Miotti, R. P. Pezzi, G. V. Soares, I. J. R. Baumvol, H.-H. Tseng, R. I. Hegde, and P. J. Tobin, Appl. Phys. Lett. 81, 1669 (2002).

${ }^{11}$ C. S. Kang, H.-J. Cho, K. Onishi, R. Choi, R. Nieh, R. Choi, S. Gopalan, K. S. J. H. Han, and J. C. Lee, Appl. Phys. Lett. 81, 2593 (2002).

${ }^{12}$ H. F. Okorn-Schmidt, IBM J. Res. Dev. 43, 351 (1999).

${ }^{13}$ I. J. R. Baumvol, Surf. Sci. Rep. 36, 1 (1999).

${ }^{14}$ M. Cho, J. Park, H. B. Park, C. S. Hwang, J. Jeong, K. S. Hyun, Y.-W. Kim, C.-B. Oh, and H.-S. Kang, Appl. Phys. Lett. 83, 1757 (2003).

${ }^{15}$ R. M. C. d. Almeida and I. J. R. Baumvol, Surf. Sci. Rep. 49, 1 (2003).

${ }^{16}$ I. J. R. Baumvol, J.-J. Ganem, L. G. Gosset, I. Trimaille, and S. Rigo, Appl. Phys. Lett. 72, 2999 (1998).

${ }^{17}$ M. L. Green, E. P. Gusev, R. Degraeve, and E. L. Garfunkel, J. Appl. Phys. 99, 2057 (2001). 